\section{TIDES OF THE ATLANTIC OCEAN}

DROF. J. PROUDMAN, professor of oceanography in the University of Liverpool, delivered the George Darwin Lecture at the Royal Astronomical Society on October 13, 1944, the subject of his lecture being "The Tides of the Atlantic Ocean" (Mon. Not. Roy. Ast. Soc., 104, 5, 244 ; 1944).

Prof. Proudman gave a short history of the problem, starting with Whewell, who published the first co-tidal charts in 1833, which were based on reasoning of a largely non-dynamical character. Whewell's deductions that the tides of the Atlantic were generated in the Southern and Pacific Oceans, which Airy rejected and which Whewell himself had abandoned by 1848, continued, unfortunately, to be repeated for a long time in text-books. In 1874 Ferrel calculated, on dynamical principles, what the tides would be in canals along parallels of latitude stretching from one side of the Atlantic to the other. $\mathrm{He}$ thought that there might be an approach to conditions of resonance for a canal between Ireland and Newfoundland, and if a dyke extended from the Cape of Good Hope to the coast of South America, the tides in the North Atlantic would probably be very nearly the same as they actually are. In 1900 Harris took up Ferrel's work, and four years later constructed charts of co-tidal lines for all the oceans and seas; but as Proudman points out, his work involved a number of serious errors, among which may be noticed a mathematical mistake involving an error of three hours in the times of high water ; the neglect of the resonance of transverse oscillations for the South Atlantic; lack of consideration of the effect of water in neighbouring regions ; and failure to give adequate consideration to the dynamical effects of the earth's rotation.

In 1910 Poincaré discussed the energy implications of progressive waves, and in applying his principle regarding the influx of energy into any region and the forces which must balance it, he concluded that, in the arctic seas, the dissipation of energy by the friction of tidal currents on the sea bottom was always negligible; that the work done against the generating force was also negligible; and that the flow of energy out of the region was insignificant on account of the smallness of the Bering Strait. $\mathrm{He}$ therefore deduced that the arctic tides do not consist of a wave progressing from the Atlantic, but, as Taylor showed in 1918 and Jeffreys in 1923, friction is by no means negligible in shallow seas, and Poincaré's arguments could not be maintained.

A brief reference is made to Sterneck's co-tidal charts, which are not based on dynamical principles, but on observation; and then Defant's work is considered at length. Defant abandoned his work of 1924 in 1932 and confined his attention to the neighbourhood of the central line of the ocean and also to the part of the Atlantic south of Iceland. He started by assuming that the rotation of the earth does not effect the tidal conditions on the central line; that the transverse generating forces do not affect tidal conditions on the central line; and that there is no dissipation of energy to the south of Iceland. $\mathrm{He}_{\theta}$ considered two phases, differing by a quarter period, such that they agree with observations at the Azores and Tristan da Cunha, the node of one phase coinciding with the loop of the other, and his results show good agreement with the observations on these islands. Although Defant's assumptions cannot be regarded as anything more than rough approxima- tions, conditions on the central line can be largely accounted for by means of longitudinal oscillations.

Prof. Proudman then turned to the results of his own researches, which are purely dynamical and are concerned with a study of a region of the Atlantic bounded by two parallels of latitude, those of $45^{\circ} \mathrm{N}$. and $35^{\circ} \mathrm{S}$. $\mathrm{He}$ supposes that we are given either: (1) the general conditions to be satisfied along the coasts and the actual meridian-components of currents across the bounding parallels; or (2) the general conditions to be satisfied at the coasts and the actual tidal elevations on the bounding parallels ; or (3) the general conditions to be satisfied at the coasts and the actual meridian-components of the currents on one bounding parallel and the actual elevations on the other bounding parallels. Then the tidal elevations and currents are mathematically determinate all over the region considered, including their values on the coasts. As we do not know the actual currents or the actual elevations or the bounding parallels, but we know the coastal elevations, the problem is considered the other way round. Given the general conditions along the coasts and the actual values of coastal elevations, the tides are mathematically determinate over the whole region considered, and Prof. Proudman solves the problem by considering a number of subsidiary problems of a different type, but limits of space prevent a detailed account of these, and a short summary of his work must suffice.

Selecting the parallel of $35^{\circ} \mathrm{S}$. as the one along which certain conditions are prescribed, and taking the elevations and meridian components of current to be zero along this parallel, but allowing for all the generating forces, one particular solution is obtained. While the resulting oscillation is small in the South Atlantic, there are larger amplitudes in the North Atlantic, and a large co-tidal area exists here. A second particular solution is an oscillation which Prof. Proudman calls a north-going Kelvin-wave, and corresponds to currents along the meridians and to elevations, both of which increase exponentially towards the west. Considerable complications are produced by the curvature of the earth along the meridians, by variations in the width of the oceans and by variations in depth. A third solution gives a south-going Kelvin-wave, and again the currents in latitude $35^{\circ} \mathrm{S}$. are along the meridian, but in this case both the elevations and currents increase exponentially towards the east. By assuming that the transverse currents follow a sine-distribution from coast to coast, two other solutions, called the north-going and the south-going Poincaré-wave, are obtained, and in these cases the amplitudes are small in the centre of the ocean.

The problem is to assign an amplitude and a timeorigin to each Kelvin- and Poincaré-wave, so that when the four are added to the forced oscillation, the coastal elevations in the synthesis will agree with observations so far as possible. Prof. Proudman has made the sum of all the waves agree with observation at four points on the coasts, and he has chosen two of these points in latitude $32 \cdot 5^{\circ} \mathrm{S}$. and the other two in latitude $7.5^{\circ} \mathrm{S}$., that is, south of the Gulf of Guinea and Cape San Roque, where the major irregularities of the basin begin. The north-going Kelvin-wave is the most important with an amplitude of $52 \mathrm{~cm}$. and a high-water time of $1.8 \mathrm{hr}$. at the south-west corner of the region considered. The south-going Poincaré-wave is the next most important ; it has an amplitude of $35 \mathrm{~cm}$. and a high-water 
time of $9.1 \mathrm{hr}$. at the south-west corner. The other two free waves have each an amplitude of $22 \mathrm{~cm}$. at the south-east corner, and the high-water time of the south-going Kelvin-wave at this point is $10.8 \mathrm{hr}$., and that of the north-going Poincaré-wave $0.5 \mathrm{hr}$. The agreement with observation is good as far as $5^{\circ} \mathrm{S}$. latitude, but considerable divergences set in afterwards. Part of this divergence may be due to not including a sufficient number of Poincaré-waves, and Prof. Proudman hopes to obtain better results by including more of these waves than he has done in the present investigations.

\section{PLANT DISEASE AND THE WEATHER}

\begin{abstract}
CLIMATE exerts an important influence on the 1 spread and severity of plant disease-an influence long recognized, though not yet fully investigated. Some recent progress in this field was discussed in a symposium arranged by the Department of Plant Pathology of the West of Scotland Agricultural College at Auchincruive on November 8. The meeting was attended by the edvisory pathologists for Scotland, the staff of the Plant Pathology Service of the Department of Agrieulture for Scotland, members of the College staff, of the University of Glasgow and the Hannah Dairy Research Institute.
\end{abstract}

Dr. C. E. Foister, head of the Plant Pathology Service of the Department of Agriculture for Scotland, opened by a short review of progress since the Conference of Empire Meteorologists in London in 1929. It becomes increasingly clear that records taken with ordinary meteorological exposure do not provide the pathologist with all the data he requires. It is necessary to study weather within the erop, and to follow up such information by investigations with artificially controlled conditions. Physiological races of fungi, moreover, may react differently to weather conditions. The distribution and occurrence of yellow rust of wheat in Scotland, for example, suggests the existence of different races varying in their reaction to environmental factors. Several parasitic fungi, common in England and Wales, are rare or unknown in Scotland, or confined to certain areas there. They include Puccinia triticina, Septoria tritici, Rhyneosporium secalis, Phytophthora cactorum, Diaporthe umbrina, Heteropatella antirrhini and the Dutch elm disease.

The rhododendron bug has twice invaded Scotland, but has failed to establish itself. How far are these apparent absences due to weather?

Dr. John Grainger, head of the Plant Pathology Department at Auchincruive, considered the aerial climate, the soil climate and the major effects of weather, with special reference to work carried out at Auchincruive in 1944. He showed how daily averages of aerial temperature and humidity inspired further work; but only continuous records within the crop revealed true phenological relationships. Chocolate spot of the field bean, bean leaf spot (Ascochyta fabce), and Erysiphe graminis on oats, all showed some increase of attack with rising relative humidity; but the real correlation was between disease intensity and the number of hours per day with complete saturation. Drain-gauge studies at Auchincruive have shown the large amount of rainfall evaporated from the soil. One aspect of aerial climate often neglected is that of conditions of storage for seed; it might be possible to provide conditions under which the parasites lose their viability before the seed. The major effects of weather are mainly important in so far as they transport fungal spores from one area to another. It has been found, however, that large teleutospores of some rust fungi are not carried more than a few yards by wind. Climate cannot, of course, be controlled, but the practical value of weather studies lies in the following points: (1) its value in lifehistory and mycological studies; (2) its help in raising immune or resistant erop varieties ; (3) virusinfected crops should be rogued within such temperature limits as the symptoms are not masked; (4) the time of farming operations can be adjusted to avoid some infections; (5) excessive atmospheric humidity may possibly be controlled in some parts of Scotland by adequate drainage; (6) conditions of seed storage may be devised to minimize seedborne disease; (7) growers may be advised when to spray in order to eliminate disease epidemics.

The role of weather as direct pathogen in causing frost damage to fruit blossom was discussed by Dr. C. E. Cornford, of the Midland Agricultural College. Field experiments with orchard heaters were described which showed that the hot air they supplied was chilled or warmed by several other agents. These included katabatic winds, altitude, the amount of cloud, the presence or absence of large dense grass exposed to the sky, the humidity of the air and the dryness of the trees and soil.

Dr. B. T. Cromwell (Auchincruive) presided over the discussion which followed. Mr. A. Heddle (Edinburgh) contrasted the epidemic of yellow rust in 1943 with its scarcity in 1944. The problem is complicated by the long growing-period of winter wheat. Dr. Mary Noble (Edinburgh) and Dr. Elizabeth Gray (Aberdeen) then contributed, and it appeared that winter wheat was generally much more susceptible than spring wheat in Scotland, and the severity of epidemics when they did occur was such that further detailed experiment was advisable. Dr. Grainger answered questions on frost damage in Dr. Cornford's absence. His own experience showed that oil heaters only raised the temperature of the air in their immediate neighbourhood by about $4^{\circ} \mathrm{F}$. Evaporation from the buds lowered their internal temperature by $2^{\circ} \mathrm{F}$., giving a net internal rise of about $2^{\circ} \mathrm{F}$. Trials with humidified heating raised the air temperature near the source by $2^{\circ} \mathrm{F}$., without internal cooling, thus resulting in a very considerable saving of fuel. Mr. Dovaston (Auchincruive) raised the question of avoiding grass cover in orchards subject to frost damage, but Dr. Cromwell and Mr. R. D. Reid (Auchincruive) held that grassing down was a very practical method of maintaining nutritional balance of the trees, particularly with regard to nitrogen.

Dr. Foister, Dr. Cromwell and Mr. Reid considered the oceurrence of Cladosporium mould in tomato glasshouses. The disease was often more severe in lowlying houses on sandy soil than in higher situations on heavy soil ; the factor of humidity did not seem to be the only one, and the admission of ultra-violet rays through 'Vita' glass did not eliminate the fungus. This discussion again pointed to the need for more detailed work. Dr. R. Laird (Ayrshire) mentioned that Ascochyta fabce and chocolate spot were more severe in low-lying, sheltered fields, but remembered that certain periods when these diseases were spreading were characterized by hot, dry days. Dr. Grainger explained, however, that long periods of complete 